\title{
A Regression Model With a New Tool: IDB Analyzer for Identifying Factors Predicting Mathematics Performance Using PISA 2012 Indices
}

\author{
Serkan Arikan \\ Mugla Sitki Kocman University, Mugla, Turkey
}

\begin{abstract}
There are many studies that focus on factors affecting achievement. However, there is limited research that used student characteristics indices reported by the Programme for International Student Assessment (PISA). Therefore, this study investigated the predictive effects of student characteristics on mathematics performance of Turkish students. In PISA studies, sampling design, sampling weights, and plausible values have to be taken into consideration in order not to have biased multiple regression results. In order to conduct multiple regression analyses in PISA, software called the International Association for the Evaluation of Educational Achievement (IEA) International Database (IDB) Analyzer is required to be used because the dependent variable consists of several plausible values. This study aims to identify student characteristics that are significant in predicting mathematics performance in Turkey. Results showed that being successful in mathematics is a combination of several factors in which students' beliefs, motivation, and other factors must be organized to achieve mathematics. Among these beliefs and motivation, strong self-efficacy, positive self-concept, and minimum level of anxiety seem to be the key for success.
\end{abstract}

Keywords: Programme for International Student Assessment (PISA) 2012, International Database (IDB) Analyzer, multiple regression, mathematics performance, PISA indices

\section{Introduction}

International comparative studies, such as the Programme for International Student Assessment (PISA), provide valuable data about student characteristics and student performance. PISA monitors the outcomes of education system of participating countries by measuring student performance on a three-year cycle and within an international common framework. With participation of more than 60 countries, PISA measures on general how well 15-year-old students are prepared to handle the challenges they may encounter in their future lives. As PISA measures not only knowledge but also skills and attitudes of students, PISA evaluates students' ability to reflect and to apply this knowledge and experience to real-life situations. PISA uses the term "literacy" to cover the broader concept of knowledge and skills in mathematics, science, and reading. The literacy concept is related to capacity of students to apply acquired knowledge and skills to different problems and challenges they encounter. For instance, students' mathematical knowledge and skills that are acquired throughout their schooling is reported as mathematical literacy score. Besides these performance data, PISA collects information

Serkan Arikan, Ph.D., assistant professor, Elementary Education Department, Mugla Sitki Kocman University. 
about students' family backgrounds, their approaches to learning, their learning environments, and their familiarity with computers (Organization for Economic Co-operation and Development (OECD), 2013b). With the use of the student characteristics data, PISA provides an opportunity to investigate factors that associated with achievement.

Over the last years, there has been an increase in the number of studies investigating student characteristics and student achievement by using PISA data (Fuchs \& Wößmann, 2007; Anderson, Lin, Treagust, Ross, \& Yore, 2007; Liang, 2010; Gilleece, Cosgrove, \& Sofroniou, 2010). These studies generally used PISA questionnaire items individually or items that were grouped by researchers. However, grouping items requires many statistical procedures; therefore, PISA also reported student characteristics indices by conducting several analyses (OECD, 2013c). Moreover, there is limited research that used these student characteristics indices. Therefore, this study sought to extend literature by investigating the predictive effects of student characteristics reported by indices in PISA 2012 on mathematics performance. The multi-faceted nature of mathematics success related to student specific variables was examined.

\section{Mathematics Performance in PISA}

PISA mathematics performance results not only reflected what a student had learned in the preceding school year, but reflected more broadly the cumulative learning up to age 15 (OECD, 2013a). The main focus of PISA assessment is not only on whether students can remember certain subject matter knowledge, but also on whether they can deduce from that knowledge and apply what they have learnt to new real-life situations. Therefore, the term "functional knowledge" and skills that are necessary to successfully participate in a society are used to define what PISA measures.

As PISA was administered in a three-year cycle, each administration focused on different subject matters. In 2012, mathematical literacy was the major domain and detailed information related to mathematics was collected, which provided an opportunity to deeply investigate factors related to mathematics performance. In PISA mathematics assessment, students are required to reflect on and evaluate given situation, not just to reach a single correct answer (OECD, 2013b). In PISA, mathematical literacy was defined broadly as:

An individual's capacity to formulate, employ, and interpret mathematics in a variety of contexts. It includes reasoning mathematically and using mathematical concepts, procedures, facts and tools to describe, explain and predict phenomena. (OECD, 2013b, p. 17)

\section{Student Characteristics in PISA}

PISA collects contextual information about students via questionnaires. In PISA 2012, the collected student level information included students and their family backgrounds, including their economic, social, and cultural capital; aspects of students' lives, such as their attitudes towards learning, their habits and life inside school, and their family environments; and availability and use of information and communication technology. Among these student characteristics, students' drive and motivation to learn mathematics and their self-beliefs as mathematics learners have special importance. Students who are not mentally ready to learn would have problems no matter whether they have best physical conditions or teachers (OECD, 2013c). Being successful is related to students' motivation, willingness to learn new things, and belief that they can achieve (Christenson, Reschly \& Wylie, 2012; Schunk \& Mullen, 2013).

In PISA 2012, students' drive and motivation and students' mathematics self-beliefs were measured under five and six dimensions respectively. Students' drive and motivation to learn mathematics were represented by 
"perseverance", "openness to problem-solving", "perceived self-responsibility for failing in mathematics", "intrinsic motivation to learn mathematics", and "instrumental motivation to learn mathematics" dimensions. On the other hand, students' mathematics self-beliefs were represented by "mathematics self-efficacy", "mathematics anxiety", "mathematics self-concept", "mathematics behaviours", "mathematics intentions", and "subjective norms in mathematics" dimensions.

PISA defines perseverance as students' willingness to work on problems that are difficult, even when they encounter problems. The index of perseverance was constructed using student responses to the following PISA questionnaire items:

When confronted with a problem, I give up easily;

I put off difficult problems;

I remain interested in the tasks that I start;

I continue working on tasks until everything is perfect;

When confronted with a problem, I do more than what is expected of me. (OECD, 2013c, p. 198)

Many researchers reported that perseverance is one of the important factors that correlates with success. Students who have low potential but high level of perseverance are more probably to be successful than students who have high potential but low level of perseverance (Duckworth, Peterson, Matthews, \& Kelly, 2007).

Openness to problem-solving is defined by PISA as students' willingness to engage with problems. The index of openness to problem-solving was constructed using student responses to the following PISA questionnaire items:

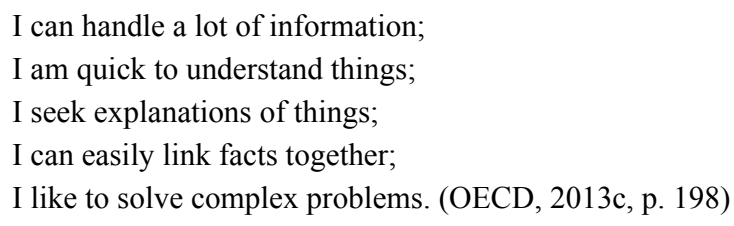

In order to be proficient in mathematics, not only subject matter knowledge, but also willingness to engage with new material, is required (OECD, 2013c).

PISA defines perceived self-responsibility for failing in mathematics as whether students attribute failure in mathematics tests to themselves or to others. The index of perceived self-responsibility for failing in mathematics was constructed using student responses to the following PISA questionnaire items:

\footnotetext{
I am not very good at solving mathematics problems;

My teacher did not explain the concepts well this week;

This week, I made bad guesses on the quiz;

Sometimes, the course material is too hard;

The teacher did not get students interested in the material;

Sometimes, I am just unlucky. (OECD, 2013c, p. 198)
}

Intrinsic motivation to learn mathematics is defined by PISA as whether students enjoy mathematics and work hard in mathematics because they enjoy the subject. The index of intrinsic motivation to learn mathematics was constructed using student responses to the following PISA questionnaire items:

I enjoy reading about mathematics;

I look forward to my mathematics;

I do mathematics because I enjoy it; 
I am interested in the things I learn in mathematics. (OECD, 2013c, p. 199)

The first variable that represents students' mathematics self-beliefs is mathematics self-efficacy. Self-efficacy is defined by Bandura (1977) as a person's belief in his/her capacity to perform at an intended level. PISA defines mathematics self-efficacy as students' perceived ability to solve a range of pure and applied mathematics problems. The index of mathematics self-efficacy was constructed using student responses about what extent they feel confident when answering the following mathematics tasks:

Using a train timetable to work out how long it would take to get from one place to another;

Calculating how much cheaper a TV would be after a 30\% discount;

Calculating how many square metres of tiles you need to cover a floor;

Understanding graphs presented in newspapers;

Solving an equation, like $3 x+5=17$;

Finding the actual distance between two places on a map with a 1:10,000 scale;

Solving an equation like $2(x+3)=(x+3)(x-3)$;

Calculating the petrol consumption rate of a car. (OECD, 2013c, p. 199)

Mathematics anxiety is defined by PISA as students' feelings of stress and helplessness when dealing with mathematics. The index of mathematics anxiety was constructed using student responses to the following PISA questionnaire items:

I often worry that it will be difficult for me in mathematics classes;
I get very tense when I have to do mathematics homework;
I get very nervous doing mathematics problems;
I feel helpless when doing a mathematics problem;
I worry that I will get poor grades in mathematics. (OECD, 2013c, p. 199)

Self-concept is defined generally as a person's perception about himself/herself (Shavelson, Hubner, \& Stanton, 1976). PISA defines mathematics self-concept as students' perceived competence in mathematics. The index of mathematics self-concept was constructed using student responses to the following PISA questionnaire items:

I am just not good at mathematics;

I get good grades in mathematics;

I learn mathematics quickly;

I have always believed that mathematics is one of my best subjects;

In my mathematics class, I understand even the most difficult work. (OECD, 2013c, p. 199)

Mathematics behaviours are defined by PISA as students' participation in a range of mathematics-related activities. The index of mathematics behaviours was constructed using student responses to the following PISA questionnaire items:

I talk about mathematics problems with my friends;

I help my friends with mathematics;

I do mathematics as an extracurricular activity;

I take part in mathematics competitions;

I do mathematics more than two hours a day outside of school;

I play chess;

I program computers;

I participate in a mathematics club. (OECD, 2013c, p. 200) 
PISA defines mathematics intentions as students intend to use mathematics in their future. The index of mathematics intention was constructed using student choices for the following pair of statements:

I intend to take additional mathematics courses after school finishes $v s$. I intend to take additional test language courses after school finishes;

I plan on majoring in a subject in college that requires mathematics skills $v s$. I plan on majoring in a subject in college that requires science skills;

I am willing to study harder in my mathematics classes than is required $v s$. I am willing to study harder in my test language classes than is required;

I plan on taking as many mathematics classes as I can during my education vs. I plan on taking as many science classes as I can during my education;

I am planning on pursuing a career that involves a lot of mathematics $v s$. I am planning on pursuing a career that involves a lot of science. (OECD, 2013c, p. 199)

The last variable was subjective norms in mathematics, which is defined by PISA as whether students' parents and peers enjoy and value mathematics. The index of subjective norms was constructed using student responses to the following PISA questionnaire items:

Most of my friends do well in mathematics;

Most of my friends work hard at mathematics;

My friends enjoy taking mathematics tests;

My parents believe it is important for me to study mathematics;

My parents believe that mathematics is important for my career;

My parents like mathematics. (OECD, 2013c, p. 200)

\section{Present Study}

PISA 2012 results showed that Turkey performed below the OECD average with a mean score of 448 in mathematics. However, PISA reported that Turkey was among the countries that increased mathematics performance and level of equity in education from 2003 to 2012 (OECD, 2013a). Although there are some improvements in PISA mathematics scores, huge achievement gap between Turkish students still exists. The score difference between the 90th and the 10th percentile mathematics performance within Turkey was over 238 points, the equivalent of more than five years of schooling. Therefore, supporting low achievers in terms of factors affecting mathematics performance in Turkish context would be effective to narrow this achievement gap and naturally improve Turkish students' overall performance.

The present study investigated the predictive effects of student characteristics measured by PISA 2012 on mathematics performance of 15-year-old students in Turkey. Therefore, in light of limited empirical research on predictive effects of student characteristics indices on mathematics performance, the present study asked the following research question: Which student characteristics are significant in predicting mathematics performance of Turkish students?

\section{Method}

\section{Sample}

The data analyzed in this study were obtained from the PISA 2012 study. In PISA, students who were aged between 15 years three months and 16 years three months and in Grade 7 or above were assessed. The sampling procedure for PISA 2012 was performed by experts from the PISA consortium. In PISA 2012 sampling procedure, two-stage stratified sample design was used. In the first stage, the sample of individual 
schools which had 15-year-old students was selected. In this selection, each school had a chance of selection proportioned to the number of their eligible 15 -year-old students. In each country, at least 150 schools were selected. In the second stage, students in sampled schools were selected with equal probability. It was achieved that the number of students selected from each school was nearly 35 (OECD, 2013b). The sample for the present study comprised all Turkish students who participated in the PISA 2012 study. The sample for Turkey consisted of 4,848 students (2,370 females and 2,478 males) who were selected among 965,736 eligible students.

\section{Measures and Variables}

Outcome variables. PISA 2012 study administered a mathematics test as one of the major subjects. PISA reported five plausible mathematics values for performance representation of each participating student. The present study used plausible mathematics values of students for mathematics performance indicator. Therefore, the dependent variable of the current study was Turkish students' mathematics performance in PISA 2012. Mathematics literacy scores were reported on a common scale with a mean of 500 and standard deviation of 100 by using the Item Response Theory.

Predictor variables. PISA reported several student level indices that reflected and summarized responses from students. Therefore, instead of using many items, a constructed scale index could be used for a common measure. These indices were constructed using a one-parameter item response model and validated using structural equation modeling by PISA experts. PISA confirmed that these indices functioned properly as theoretically expected by conducting structural equation modeling analyses for each country separately and for all OECD countries together. The indices were standardized in a way that the mean for OECD students was 0 and standard deviation was 1 (OECD, 2013c). It is important to note that a negative value implies that a student responded less positively than all other students responded on average across OECD countries. Similarly, a student with positive score on the index is a student who responded more positively than the average OECD students do (OECD, 2013c).

In PISA 2012, students were expected to report their drive and motivation to learn mathematics and their self-beliefs as mathematics learners. Students' drive and motivation to learn mathematics were represented by indices: perseverance, openness to problem-solving, perceived self-responsibility for failing in mathematics, intrinsic motivation to learn mathematics, and instrumental motivation to learn mathematics. On the other hand, mathematics self-beliefs were represented by indices: mathematics self-efficacy, mathematics anxiety, mathematics self-concept, mathematics behaviours, mathematics intentions, and subjective norms in mathematics.

The present study used PISA student questionnaire indices for student characteristics indicator. Therefore, student characteristics indices on the PISA 2012 assessment related to students' drive and motivation to learn mathematics and mathematics self-beliefs were the independent variables of the study.

\section{The Procedure for Data Analysis}

In the current study, using PISA student characteristics indices as independent variables and mathematics performance as the dependent variable, a multiple regression analysis was conducted. In multiple regression analyses, relationships between one dependent variable and several independent variables are investigated. Specifically, multiple regression analysis results are used to identify important independent variables that predict variation in a dependent variable. In this study, student indices that were statistically significant and relatively important in predicting mathematics performance were identified. 
In order to conduct multiple regression analyses in PISA, software called the International Association for the Evaluation of Educational Achievement (IEA) International Database (IDB) Analyzer (IEA, 2013) is required to be used. IDB Analyzer, developed by the IEA Data Processing and Research Center in Hamburg, Germany, analyzes IEA's large-scale assessments, such as PISA. In PISA studies, sampling design, sampling weights, and plausible values have to be taken into consideration in order not to have biased conclusions. IDB Analyzer first produces a Statistical Package for the Social Science (SPSS) syntax which takes into account sampling design, sampling weights, and plausible values reported in PISA. Then, by using this syntax, SPSS can conduct multiple regression analysis and estimate regression coefficients for independent variables which predict a dependent variable even if the dependent variable consists of several plausible values, like in PISA (IEA, 2013). Therefore, this study is unique in investigating factors, reported as indices, and predicting mathematics performance in PISA by using IDB Analyzer.

\section{Results}

Descriptive statistics for all predictor variables used in the study are reported in Table 1. These values imply that Turkish students got higher indices score than all other students responded on average across OECD countries on perseverance, openness to problem-solving, perceived self-responsibility for failing in mathematics, intrinsic motivation to learn mathematics, mathematics self-efficacy, mathematics anxiety, mathematics behaviours, mathematics intentions, and subjective norms in mathematics. However, Turkish students had lower indices score than all other students responded on average across OECD countries on instrumental motivation to learn mathematics and mathematics self-concept.

Table 1

Descriptive Statistics of Predictor Variables

\begin{tabular}{lll}
\hline & $M$ & $S D$ \\
\hline Perseverance & 0.39 & 1.06 \\
Openness to problem-solving & 0.26 & 0.97 \\
Perceived self-responsibility for failing in mathematics & 0.28 & 1.11 \\
Intrinsic motivation to learn mathematics & 0.40 & 1.11 \\
Instrumental motivation to learn mathematics & -0.01 & 1.00 \\
Mathematics self-efficacy & 0.02 & 0.95 \\
Mathematics anxiety & 0.32 & 0.97 \\
Mathematics self-concept & -0.04 & 0.96 \\
Mathematics behaviours & 0.61 & 1.04 \\
Mathematics intentions & 0.17 & 1.00 \\
Subjective norms in mathematics & 0.27 & 1.18 \\
\hline
\end{tabular}

Multiple regression analysis was used to explain what main factors were important in predicting PISA 2012 mathematics performance of Turkish students by using student characteristics reported by indices. Multiple regression analysis conducted by IDB Analyzer showed that the overall regression models predicting mathematics performance from student indices were statistically significant for Turkish students, adjusted $R^{2}=0.27, F(10,4837)=176.57$, and $p<0.01$. Among 11 predictor variables, seven of them had statistically significant contribution in predicting PISA 2012 mathematics performance (see Table 2). These significant variables were perseverance, intrinsic motivation to learn mathematics, mathematics self-efficacy, mathematics anxiety, mathematics self-concept, mathematics behaviours, and mathematics intentions. Altogether, these 
variables explained $27 \%$ of the variability in the Turkish students' mathematics performance in PISA 2012. The variables - openness to problem-solving, perceived self-responsibility for failing in mathematics, instrumental motivation to learn mathematics, and subjective norms in mathematics — had no statistically significant predictive effects on students.

Table 2

Multiple Regression Results Investigating the Associations Between the PISA 2012 Student Questionnaire Indices and Turkish Students' Mathematics Performance

\begin{tabular}{lccc}
\hline PISA 2012 indices & Unstandardized $\beta$ weight & Standardized $\beta$ weight & $t$ \\
\hline Perseverance & -4.74 & -0.06 & $-2.12^{*}$ \\
Openness to problem-solving & 0.82 & 0.01 & 0.27 \\
Perceived self-responsibility for failing in mathematics & -2.13 & -0.03 & -0.89 \\
Intrinsic motivation to learn mathematics & -14.67 & -0.18 & $-3.88^{*}$ \\
Instrumental motivation to learn mathematics & -1.73 & -0.02 & -0.52 \\
Mathematics self-efficacy & 45.40 & 0.48 & $14.18^{*}$ \\
Mathematics anxiety & -16.15 & -0.18 & $-5.77^{*}$ \\
Mathematics self-concept & 9.50 & 0.10 & $2.31^{*}$ \\
Mathematics behaviours & -11.86 & -0.14 & $-4.73^{*}$ \\
Mathematics intentions & 6.80 & 0.08 & -0.04 \\
Subjective norms in mathematics & -2.89 & $-41^{*}$ \\
\hline
\end{tabular}

Note. ${ }^{*}$ Statistically significant $t$ values at $p<0.05$ level.

The significant negative $\beta$ weights for each predictor variable indicate that students with higher score in perseverance, intrinsic motivation to learn mathematics, mathematics anxiety, and mathematics behaviours showed lower mathematics performance in PISA 2012. The significant positive $\beta$ weights for each predictor variable indicate that students with higher score in mathematics self-efficacy, mathematics self-concept, and mathematics intentions showed higher mathematics performance in PISA 2012.

These results also implied that among five variables related to students' drive and motivation to learn mathematics, only two of them had a significant effect on predicting mathematics performance (standardized $\beta$ weight ranges from -0.06 to -0.18). However, among six variables related to students' mathematics self-beliefs, five of them had a significant effect on predicting mathematics performance (standardized $\beta$ weight ranges from -0.18 to 0.48 ).

\section{Discussion and Conslusion}

This study sought to determine the role of Turkish students' belief, drive, and motivation on PISA 2012 mathematics achievement. Students' belief, drive, and motivation that they can be successful are required than just cognitive proficiency (OECD, 2013c). There is no single combination of student characteristics that will increase achievement for every nation. Every country might have its own way to increase achievement of low achievers. In order to evaluate a nation's mathematics performance and factors predicting achievement, PISA results have special importance. Longitudinal studies showed that PISA results were highly correlated with students' success on their future lives (OECD, 2010; OECD, 2012). As the results showed, perseverance, intrinsic motivation to learn mathematics, mathematics self-efficacy, mathematics anxiety, mathematics self-concept, mathematics behaviours, and mathematics intentions had significant effects on predicting Turkish students' mathematics performance. 
The most affective factor among these significant predictors was mathematics self-efficacy (standardized $\beta$ weight $=0.48$ ). This value implies that as a student's self-efficacy increases, so does his/her mathematics performance. This result is consistent with the other studies (Randhawa, Beamer, \& Lundberg, 1993; Shen, 2002; Lee, 2009; Kitsantas, Cheema, \& Ware, 2011). Turkish students reported that they had very close mathematics self-efficacy level (mean value of 0.02 ) as OECD average. However, this level of self-efficacy was not sufficient for Turkish students to perform above OECD average on mathematics. Efficacy beliefs affect people's feelings, thinking, motivation, and behaviours. As perceived self-efficacy is getting stronger, people set more challenging goals and commit firmly to these goals. Possessing knowledge and skills does not guarantee that someone can use it in all conditions. Therefore, two students with the same knowledge and skills may perform very differently depending on self-efficacy levels (Bandura, 1993). The results of this study and Bandura's explanations imply that increasing students' self-efficacy, especially low achieving students' self-efficacy, is expected to increase the overall mathematics performance. Therefore, strategies that are helpful to increase students' self-efficacy should be utilized. The way feedback is given affects self-efficacy. Bandura (1993) proposed that feedbacks that emphasized achieved progress highlight personal capabilities, whereas feedbacks that emphasized shortcomings highlight personal deficiencies. This implies that if teachers praise students on their strong academic capabilities and try to remedy deficiencies by using students' successful skills, self-efficacy level would increase. Kitsantas et al. (2011) advised that classroom and homework assignments should be designed in a way that students feel efficacious in working on mathematics contents. Teachers should provide mastery experiences where students can taste the feeling of success. Organizing tasks that progress from the easy to the more difficult and from simple recalling to analysis, synthesis, or evaluation while reinforcing students' self-efficacy is necessary for success. Besides that, there are some educational practices that would lower self-efficacy. Bandura (1993) stated that if a student sees that other students surpass him/her, this situation will probably lower his/her self-efficacy. In Turkey, starting from the first grade, there is a widespread practice of ordering students according to classroom level, school level, and even country level examination results. Therefore, starting from early years of education, many students undermine his/her self-efficacy as they perform at low or middle level.

The result of this study also proposed that the greater the students have self-concepts, the higher their mathematics score (standardized $\beta$ weight $=0.10$ ). The positive effect of self-concept on mathematics performance was also found by other studies (Marsh, 1986; Abu-Hilal, 2000). The current study also implied that self-efficacy was a stronger predictor of success than self-concept. Similarly, in many studies, it is deduced that mathematics self-efficacy was more predictive than mathematics self-concept on mathematics performance (Pajares \& Miller, 1994; Lee, 2009). Bong and Skaalvik (2003) proposed that it is hard to differentiate between self-efficacy and self-concept. However, they added that self-concept is a general perception of a person whereas self-efficacy is related to a person's expectation and conviction about given specific situation. In this study, correlation between self-efficacy and self-concept was estimated as 0.49 . This moderate level of correlation implies that self-efficacy and self-concept were not totally same in the PISA. Besides, the distinction between self-concept and self-efficacy could be seen in questionnaire items. Items measuring self-concept are more general whereas items measuring self-efficacy are more situations specific. Turkish students reported that they had less mathematics self-concept level (mean value of -0.04) than OECD average. Therefore, educational practices that are expected to promote self-concept would be beneficial to increase Turkish students' PISA performance. 
Results also indicated that mathematics anxiety is inversely related with mathematics achievement ( standardized $\beta$ weight $=-0.18$ ). Many studies showed that there is a negative correlation between mathematics anxiety and mathematics achievement, therefore, Hembree (1990) and Ma (1999) conducted meta-analysis on these findings. Descriptive statistics in Table 1 showed that Turkish students have a higher level of anxiety on average than OECD students (0.32). As Turkish students' average self-efficacy and self-concept were close to OECD average, the high level of anxiety implies that serious actions should be taken to lower this general mathematics anxiety level. In their study, Ma and Xu (2004) concluded that low mathematics achievement in early school year affected high mathematics anxiety in later years, however, prior high mathematics anxiety was less effective in poor mathematics performance in later years. Therefore, from early years of education, students should engage with mathematics activities that they can cope with. Therefore, adapting questions and activities according to student level becomes an important issue of teachers. Using computer-adaptive programs (Math Garden) (Klinkenberg, Straatemeimer, \& Van der Maas, 2011) would ease the job of teachers to decrease anxiety level of students (Jansen, Louwerse, Straatemeier, Van der Ven, Klinkenberg, \& Van der Maas, 2013).

Another factor that has positive association with mathematics performance is mathematics intentions (standardized $\beta$ weight $=0.08$ ). PISA defined mathematics intentions as students' willingness to use mathematics in the future. Turkish students reported that they had higher intention level than OECD average (0.17). This is mainly related to that the Turkish society believes that mathematics is a must to be successful in the future. Especially parents give importance to mathematics and believe that mathematics is essential to be successful in the future, especially in university entrance examinations. However, high family pressure for higher achievement is known to be associated with mathematics anxiety (McLeod, Wood, \& Weisz, 2007; Wood, Mcleod, Sigman, Hwang, \& Chu, 2003), which is also higher in Turkish students. Students with high level of anxiety enjoy mathematics less, become less confident, and steer away from mathematics courses (Ashcraft, 2002), which might result in lower mathematics intentions in the future. Therefore, there is a need to increase students' mathematics intention levels without increasing their anxiety level. There are projects in the form of summer project that aim to increase students' interest to mathematics (Hayden, Ouyang, Scinski, Olszewski, \& Bielefeldt, 2011). Activating such programs in Turkey is expected to increase students' mathematics intentions more.

Among other significant factors, intrinsic motivation to learn (standardized $\beta$ weight $=-0.18$ ), mathematics behaviours (standardized $\beta$ weight $=-0.14$ ), and perseverance ( standardized $\beta$ weight $=-0.06$ ) showed negative correlation with mathematics performance of Turkish students. These values indicated that holding mathematics self-efficacy, self-concept, mathematics anxiety, and mathematics intentions constant, change in these variables results in negative change in mathematics performance.

Being successful in mathematics is not just related to knowing mathematics. Rather, it is a combination of several factors in which students' beliefs, motivation, and other factors must be organized to achieve mathematics. Building learning environments that promote beliefs and motivation which correlate with achievement is essential for academic success. Among these beliefs and motivation, strong self-efficacy, positive self-concept, and minimum level of anxiety seem to be the key for success. In Turkey, many teachers claimed that solving thousands of items as a classroom activity is the best way to reach to the success. However, this kind of activities increases achievement gap by focusing on only successful students and forgetting other students. As this study showed, increasing all students' self-efficacy and self-concept level whereas decreasing their anxiety level would ease their job. 


\section{Limitations}

The indices related to students' drive and self-beliefs that used in this study were based on students' self-reports. Therefore, these indices might have some amount of measurement error (OECD, 2013c). Buckley (2009) stated that students from countries with low gross domestic product (GDP) or students with lower socio-economic background and less education tend to give more socially desirable responses that produce response bias. This situation is one of the limitations of this study. This study is also limited to the mathematics items that were used to measure mathematics success in PISA. The quality assurance of original items, Turkish adaptation of examination, and statistical procedures to estimate mathematics scores are all conducted by the PISA consortium. The researcher had no impact on these procedures.

\section{References}

Abu-Hilal, M. M. (2000). A structural model for predicting mathematics achievement: Its relation with anxiety and self-concept in mathematics. Psychological Reports, 86(3), 835-847.

Anderson, J. O., Lin, H. S., Treagust, D. F., Ross, S. P., \& Yore, L. D. (2007). Using large-scale assessment datasets for research in science and mathematics education: Programme for International Student Assessment (PISA). International Journal of Science and Mathematics Education, 5(4), 591-614.

Ashcraft, M. H. (2002). Math anxiety: Personal, educational, and cognitive consequences. Current Directions in Psychological Science, 11, 181-185.

Bandura, A. (1977). Self-efficacy: Toward a unifying theory of behavioral change. Psychological Review, 84(2), 191-215.

Bandura, A. (1993). Perceived self-efficacy in cognitive development and functioning. Educational Psychologist, $28,117-148$.

Bong, M., \& Skaalvik, E. M. (2003). Academic self-concept and self-efficacy: How different are they really? Educational Psychology Review, 15(1), 1-40.

Buckley, J. (2009). Cross-national response styles in international educational assessments: Evidence from PISA 2006. Retrieved June 11, 2014, from https://edsurveys.rti.org/PISA/documents/Buckley_PISAresponsestyle.pdf

Christenson, S. L., Reschly, A. L., \& Wylie, C. (Eds.). (2012). Handbook of student engagement. New York, N.Y.: Springer.

Duckworth, A. L., Peterson, C., Matthews, M. D., \& Kelly, D. R. (2007). Grit: Perseverance and passion for long-term goals. Journal of Personality and Social Psychology, 92(6), 1087-1101.

Fuchs, T., \& Wößmann, L. (2007). What accounts for international differences in student performance? A re-examination using PISA data. Empirical Economics, 32, 433-464.

Gilleece, L., Cosgrove, J., \& Sofroniou, N. (2010). Equity in mathematics and science outcomes: Characteristics associated with high and low achievement on PISA 2006 in Ireland. International Journal of Science and Mathematics Education, 8(3), 475-496.

Hayden, K., Ouyang, Y., Scinski, L., Olszewski, B., \& Bielefeldt, T. (2011). Increasing student interest and attitudes in STEM: Professional development and activities to engage and inspire learners. Contemporary Issues in Technology and Teacher Education, 11(1), 47-69.

Hembree, R. (1990). The nature, effects, and relief of mathematics anxiety. Journal for Research in Mathematics Education, 21, 33-46.

International Association for the Evaluation of Educational Achievement (IEA). (2013). IDB Analyzer (Computer software and manual). Hamburg, Germany: IEA.

Jansen, B. R. J., Louwerse, J., Straatemeier, M., Van der Ven, S. H., Klinkenberg, S., \& Van der Maas, H. L. (2013). The influence of experiencing success in math on math anxiety, perceived math competence, and math performance. Learning and Individual Differences, 24, 190-197.

Kitsantas, A., Cheema, J., \& Ware, H. W. (2011). Mathematics achievement: The role of homework and self-efficacy beliefs. Journal of Advanced Academics, 22(2), 310-339.

Klinkenberg, S., Straatemeier, M., \& Van der Maas, H. L. J. (2011). Computer adaptive practice of maths ability using a new item response model for on the fly ability and difficulty estimation. Computers in education, 57, 1813-1824.

Lee, J. (2009). Universals and specifics of math self-concept, math self-efficacy, and math anxiety across 41 PISA 2003 participating countries. Learning and Individual Differences, 19(3), 355-365. 
Liang, X. (2010). Assessment use, self-efficacy and mathematics achievement: Comparative analysis of PISA 2003 data of Finland, Canada and the USA. Evaluation \& Research in Education, 23(3), 213-229.

Ma, X. (1999). A meta-analysis of the relationship between anxiety toward mathematics and achievement in mathematics. Journal for Research in Mathematics Education, 30, 520-540.

Ma, X., \& Xu, J. M. (2004). The causal ordering of mathematics anxiety and mathematics achievement: A longitudinal panel analysis. Journal of Adolescence, 27(2), 165-179.

Marsh, H. W. (1986). Verbal and math self-concepts: An internal/external frame of reference model. American Educational Research Journal, 23(1), 129-149.

McLeod, B. D., Wood, J. J., \& Weisz, J. R. (2007). Examining the association between parenting and childhood anxiety: A meta-analysis. Clinical Psychology Review, 27, 155-172.

Organization for Economic Co-operation and Development (OECD). (2010). Pathways to success: How knowledge and skills at age 15 shape future lives in Canada. Paris: OECD Publishing. Retrieved from http://dx.doi.org/10.1787/9789264081925-en

OECD. (2012). Learning beyond fifteen: Ten years after PISA. Paris: OECD Publishing. Retrieved from http://dx.doi.org/10.178 7/9789264172104-en

OECD. (2013a). PISA 2012 results: What students know and can do-Student performance in mathematics, reading and science (Volume I). Paris: OECD Publishing. Retrieved from http://dx.doi.org/10.1787/9789264201118-en

OECD. (2013b). PISA 2012 assessment and analytical framework: Mathematics, reading, science, problem solving and financial literacy. Paris: OECD Publishing. Retrieved from http://dx.doi.org/10.1787/9789264190511-en

OECD. (2013c). PISA 2012 results: Ready to learn: Students' engagement, drive and self-beliefs (Volume III). Paris: OECD Publishing. Retrieved from http://dx.doi.org/10.1787/9789264201170-en

Pajares, F., \& Miller, M. D. (1994). Role of self-efficacy and self-concept beliefs in mathematical problem solving: A path analysis. Journal of Educational Psychology, 86(2), 193-203.

Randhawa, B. S., Beamer, J. E., \& Lundberg, I. (1993). Role of mathematics self-efficacy in the structural model of mathematics self-efficacy in the structural model of mathematics achievement. Journal of Educational Psychology, 85 (1), 41-8.

Schunk, D. H., \& Mullen, C. A. (2013), Motivation. In J. Hattie, \& E. M. Anderman (Eds.), International guide to student achievement (pp. 67-69). New York, N.Y.: Routledge.

Shavelson, R. J., Hubner, J. J., \& Stanton, G. C. (1976). Self-concept: Validation of construct interpretations. Review of Educational Research, 46, 407-441.

Shen, C. (2002). Revisiting the relationship between students' achievement and their self-perceptions: A cross-national analysis based on TIMSS 1999 data. Assessment in Education: Principles, Policy and Practice, 9(2), 161-184.

Wood, J. J., McLeod, B. D., Sigman, M., Hwang, W., \& Chu, B. C. (2003). Parenting and childhood anxiety: Theory, empirical findings, and future directions. Journal of Child Psychology and Psychiatry, 44, 134-151. 